\title{
O ADOLESCENTE E A DEFICIÊNCIA AUDITIVA: AS RELAÇÕES FAMILARES RETRATADAS NO TESTE DO DESENHO EM CORES DAFAMÍLIA
}

\section{THE ADOLESCENT AND THE HEARING LOSS: THE PORTRAIED FAMILY RELATIONS IN THE TEST OF THE DRAWING IN COLORS OF THE FAMILY}

\author{
Luciana Maria Biem Neuber * \\ Tania Gracy Martins Do Valle ** \\ Maria Estela Guadagnucci Palamin ***
}

Neuber LMB, Valle TGM, Palamin MEG. O Adolescente e a Deficiência Auditiva: As Relações Familares Retratadas no Teste do Desenho em Cores da Família. Rev Bras Crescimento Desenvolvimento Hum. 2008; 18(3): 321-338

\section{Resumo:}

A presente pesquisa tem por finalidade investigar os componentes emocionais e dificuldades envolvidas na dinâmica familiar de adolescentes portadores de deficiência auditiva, visto que a família necessita lidar com os aspectos biopsicossociais da adolescência e da deficiência. Participaram deste estudo oito adolescentes, com idade de doze a dezoito anos, de ambos os sexos, juntamente com seus pais. O Teste do Desenho em Cores da Família TDCF instrumento utilizado, foi aplicado em todos os participantes da pesquisa, individualmente. Cada indivíduo desenhou sua família, respondendo ao questionário do instrumento. Assim sendo, fundamentada na abordagem sistêmica, foi possível visualizar o contexto familiar na particularidade de cada membro envolvido, bem como o panorama geral da estruturação familiar. Portanto, constatou-se que a deficiência auditiva gera disfunções apresentadas através das dimensões interacionais, tais como comunicação, conflitos, afeição e integração, refletindo nos pais os sentimentos de medo e insegurança, e nos filhos, de repressão e dependência.

Palavras chave: Adolescente; deficiência auditiva; psicologia; relação familiar.

Pesquisa realizada no Centro de Atendimento aos Distúrbios de Audição, Linguagem e Visão (CEDALVI), do Hospital de Reabilitação de Anomalias Craniofaciais, no setor de Psicologia, localizado na cidade de Bauru-SP.

* Centro de Estudos Homo Sapiens. Rua Benedito Moreira Pinto, 1-38. Jardim Panorama. 17011-110 Bauru-SP

** Universidade Estadual Paulista - UNESP. Av. Engenheiro Luiz Edmundo Carrijo Coube, S/N. 17033-380. Bauru-SP

*** Centro de Atendimento aos Distúrbios de Audição, Linguagem e Visão do Hospital de Reabilitação de Anomalias Craniofaciais da Universidade de São Paulo - HRAC. Rua Benedito Moreira Pinto, 8-81. Jardim Panorama. 17011-110. Bauru-SP. Correspondência para: Luciana Maria Biem Neuber. Rua Benedito Moreira Pinto, 1-38. Jardim Panorama. 17011-110 BauruSP. Fone/Fax:(14) 3227-0624/(14) 8141-0881 - Email: lmbn_psi@hotmail.com 


\begin{abstract}
:
Present research aimed to investigate the emotional components and the difficulties involved in family dynamics of hearing impaired adolescents, since family has to deal with biopsychosocial aspects of adolescence and deficiency. Eight adolescents, aged between twelve and eighteen years old, both sexes, and their parents took part in the study. Family Colored Drawing Test - FCDT the employed tool, has been submitted individually to the adolescents and their parents. Each participant drew his (her) family and asked to the tool questionnaire. Thus, based in systemic approach, familiar context could be visualized in the particularity of each involved member, as well as general view of family structure. Therefore, it was observed that hearing deficiency causes dysfunctions that are shown through interactional dimensions, such as communication, conflicts, affection and integration, reflecting upon parents fear and unsafety, and upon their children, repression and dependency.
\end{abstract}

Key words: Adolescent; hearing loss; psychology; family relations.

\section{INTRODUÇÃO}

A teoria sistêmica possui um importante referencial teórico para que a família seja compreendida como um sistema complexo. Este novo conhecimento revolucionou as ciências exatas e biológicas e influenciou significativamente as ciências sociais no século XX. Diante da necessidade de realizar estudos para compreender determinados fenômenos, verificou-se que o modelo de causalidade linear (causa e efeito) não fornecia subsídios suficientes e passou-se a ter uma visão complexa da realidade na qual o todo é constituído por partes e ambos influenciam-se mutuamente. ${ }^{1,2}$

Segundo a teoria sistêmica, a família é um sistema vivo e funciona de acordo com alguns princípios básicos, tais como: o sistema é um todo organizado; os padrões, em um sistema, são circulares e não lineares, isto é, há influência mútua e bidirecionalidade entre os seus membros; os sistemas vivos são abertos (estabelecem trocas com o ambiente externo) que, por sua vez provocam transformações no sistema, além de possuírem elementos homeostáticos e mecanismos de reequilibração que mantêm a estabilidade de seus padrões; e são sistemas complexos compostos por subsistemas interdependentes. Assim sendo, a família é considerada como um todo, no qual os seus membros possuem uma estrutura, uma dinâmica e uma função na busca de um equilíbrio homeostático, regulados pelo princípio de retroalimentação. ${ }^{3-5}$

Dentro do âmbito familiar encontramse três subsistemas: o conjugal (casal), o parental (pais e filhos) e o fraternal (irmãos), os quais são delimitados por fronteiras, podendo ser rígidas (relações difíceis, fechadas), difusas (relações dependentes) ou nítidas (relações abertas). As fronteiras têm como função proteger, delimitar e estabelecer trocas com o meio. A permeabilidade entre os subsistemas é saudável e deve existir, para que a homeostase familiar mantenha-se em equilíbrio. ${ }^{6}$

Cada família é única em função da sua organização estrutural. Dessa forma, o processo de desenvolvimento familiar compreende mudanças grupais e individuais, passando por transformações fundamentais na estruturação familiar, denominada ciclo vital, o qual compreende a formação do novo casal, família com filhos pequenos, família com filhos na escola, família com filhos adolescentes, família com filhos adultos e a família no estágio tardio da vida. Assim sendo, as famílias vivenciam fases de transição, cada qual caracterizada espe- 
cificamente através de situações e conflitos diferenciados. $^{7}$

A pesquisa em questão abrange as famílias em fase do ciclo vital na adolescência, momento este que, geralmente, envolve mudanças na estrutura e na renegociação de papéis entre três gerações: a dos filhos entrando na adolescência, os pais caminhando para a entrada na meia - idade e os avós enfrentando a velhice. As três gerações sofrem fases de transição conflituosas que, basicamente, implicam um salto para uma nova etapa mais amadurecida.

A fase da adolescência é conceituada, por alguns autores, cronologicamente iniciando aos onze e terminando aos vinte anos. Definir o adolescente torna-se complexo em virtude das inúmeras descrições encontradas na literatura, devido aos variados componentes manifestos nesta etapa de vida. As transformações biológicas, psicológicas e sociais são indiscutivelmente aspectos envolvidos na transição da fase infantil para a fase adulta. ${ }^{8}$

Momento crucial na vida do indivíduo, considerada etapa decisiva do processo de desprendimento iniciado com o nascimento, a adolescência é um período de contradições, confusões, ambivalências na tentativa de integração da própria personalidade. ${ }^{9}$

Nesta etapa do ciclo vital familiar sentimentos ambivalentes predominam, de um lado adolescentes buscando liberdade, autonomia e do outro, pais exigindo responsabilidade, compromisso e amadurecimento. Pais e filhos adolescentes estão passando por profundas mudanças orgânicas e psíquicas, os pais querem que os filhos cresçam e ao mesmo tempo continuem eternas crianças, pois sentem a idade passando e vivem a dificuldade de encarar a entrada na meia-idade. Já os adolescentes reivindicam serem tratados como adultos, mas agem impulsivamente, apressadamente, como se o mundo fosse acabar a qualquer momento, com resquícios de atitudes infantis. ${ }^{4}$
Esta fase envolve questões geradoras de preocupações e conflitos entre pais e filhos, diante da demanda de exigências a serem enfrentadas em vários aspectos como, entre outros, a sexualidade, as drogas, a violência, os estudos, o futuro profissional e os limites. ${ }^{7}$

Pesquisas realizadas sobre educação sexual e adolescência revelam que as informações sobre a sexualidade são obtidas em primeiro lugar com os colegas da mesma idade, em segundo lugar com as mães e em terceiro lugar com os professores. Os adolescentes relatam que preferiam que os pais fossem mais abertos, pois dão informações insuficientes e têm reações negativas diante de cenas de sexo na TV. Os dados apontam que os pais desconhecem a vida sexual ativa dos filhos, principalmente das filhas. ${ }^{10-12}$

Vitiello et $\mathrm{al}^{8}$ ressaltam que dúvidas e curiosidades dos adolescentes em assuntos como sexualidade e relacionamentos afetivos são muitas vezes dúvidas até hoje prolongadas pelos próprios pais, pois esbarram num contexto histórico de repressão sexual no passado e liberdade atual. Os pais que, geralmente, estão com sua sexualidade bem resolvida, tabus e dúvidas esclarecidas sentem-se mais preparados para conversarem com o adolescente e lidam com o assunto naturalmente.

Os perigos do mundo externo, como as drogas e a violência, também são alvos de temores dos pais, os quais ficam paralisados sem saber o que fazer e como prevenir seu filho dos males da vida.

Inúmeros são os fatores que podem levar o adolescente ao uso de substâncias psicoativas, desde sociais, familiares e pessoais. Socialmente o grupo de amigos desempenha um importante papel na forma de pensar e agir do adolescente, à medida que pertencer a uma turma é vital nesta fase. O adolescente possui um vínculo mais intenso com a turma do que com os pais, neste período, sofrendo influência direta do meio em seu comportamen- 
to. No contexto familiar do adolescente é freqüente encontrar pais com diferentes tipos de adição e/ou ainda ambientes hostis nos quais a desestrutura familiar pode possibilitar o uso de drogas. ${ }^{13-15}$

O diálogo, compreendido como a expressão de opiniões por parte de todos os envolvidos, sustentado no respeito mútuo, entre pais e filhos adolescentes, é fundamental para que o jovem sinta-se acolhido e possa expressar seus medos, dúvidas, angústias, enfim todos os sentimentos presentes nesta fase. ${ }^{16}$

A deficiência auditiva é considerada uma perda dos órgãos sensoriais, congênita ou adquirida, com causas diversas, podendo ou não impedir a aquisição da linguagem. Assim sendo, o portador de deficiência auditiva será acometido no aspecto físico, psicológico e social de sua vida. ${ }^{17}$

Silman e Silverman ${ }^{18}$ classificam o tipo de deficiência auditiva como: Condutiva: aquela que resulta de patologias que atingem a orelha externa e/ou média; Sensorioneural: a que resulta de distúrbios que comprometem o nervo vestibulococlear e nervo coclear; Mista: aquela que apresenta componente condutivo (orelha externa e/ou média) e sensorioneural (nervo vestibulococlear e nervo coclear) em uma mesma orelha. E em relação ao grau da perda, classificam - Crianças: Perda Mínima: 16 a 25 dBNA; Crianças e adultos: Perda leve 26 a 40 dbNA; Perda Moderada: 41 a 55 dBNA; perda moderadamente severa: 56 a 70 dBNA; Perda Severa: 71 a 90 dBNA e Perda Profunda acima de 90 dBNA (dBNA - deciBel Nível de Audição).

O portador de deficiência auditiva possui dificuldades em comunicar-se com o mundo, fazer-se compreender e ser compreendido. A família fornece ao indivíduo o primeiro contato com as relações humanas, desempenhando importante papel para a socialização. O contexto familiar do deficiente auditivo exigirá paciência e carinho, por parte de todos os membros, para que possa, além de cumprir o seu papel habitual, fornecer subsídios ao deficien- te na aprendizagem da linguagem. Os pais devem incentivar a compreensão e solidariedade, principalmente, na relação entre os irmãos ouvintes com o portador de deficiência auditiva. A afetividade é fundamental, à medida que será através das relações familiares que o indivíduo apreenderá o mundo. ${ }^{17}$

Isto posto, a família, com um membro em fase de adolescência portador de deficiência auditiva, necessitará lidar tanto com as demandas exigidas pela idade como os aspectos biopsicossociais envolvidos nos distúrbios de audição.

O Centro de Atendimento aos Distúrbios de Audição, Linguagem e Visão (CEDALVI), do Hospital de Reabilitação de Anomalias Craniofaciais (HRAC), da Universidade de São Paulo (USP), localizado em Bauru-SP, onde foi realizada a pesquisa, tem como objetivo a habilitação, reabilitação e integração de seus pacientes. O trabalho é integrado e realizado por uma equipe composta de médicos, fonoaudiólogos, psicólogos, assistentes sociais, enfermeiros, nutricionistas e fisioterapeutas. ${ }^{19}$

$\mathrm{O}$ interesse pela presente pesquisa justifica-se mediante o pequeno número de estudos disponíveis na literatura com adolescentes portadores de deficiência auditiva em seu contexto familiar, através do referencial sistêmico.

A motivação para a realização deste trabalho partiu de queixas individualizadas de adolescentes e pais na prática clínica. Assim sendo, surgiu a necessidade de compreender o olhar dos membros familiares (pais e adolescentes) tanto referente ao aspecto da fase da adolescência quanto da deficiência.

Portanto, tem como objetivo verificar os componentes emocionais e dificuldades envolvidas na dinâmica familiar de adolescentes com deficiência auditiva.

\section{MÉTODO}

O critério de seleção dos participantes envolveu a idade cronológica, devido à pes- 
quisa ter como finalidade estudar as famílias em fase do ciclo vital na adolescência, a constelação familiar, sendo os pais casados e ambos comprometidos em participarem da pesquisa e o tipo de perda auditiva, preferencialmente com perda de audição de grau leve a moderada, devido à necessidade de comunicação oral.

A pesquisa foi realizada com oito adolescentes portadores de deficiência auditiva, pacientes do Centro de Atendimento aos Distúrbios de Audição, Linguagem e Visão (CEDALVI), com idade de 12 a 18 anos, e seus respectivos pais.

O instrumento utilizado para a realização da presente pesquisa é o Teste do Desenho em Cores da Família - TDCF, sistematizado por Corman ${ }^{22}$ e adaptado por Retondo ${ }^{1}$, considerado uma técnica projetiva gráfica, com a finalidade de visualizar o panorama geral da estrutura familiar, vista pela ótica do sujeito, através do desenho em cores da família, bem como analisar as disfuncionalidades envolvidas de acordo com as dimensões interacionais.

Os instrumentos que compõem o teste incluem a Ficha de Identificação, o Roteiro de Observação do Sujeito (Anexo 1), o Quadro Referencial para análise do TDCF (Anexo 2) a Folha de Avaliação, contendo as dimensões interacionais, bem como o questionário (Anexos 3 e 4) o qual foi adaptado à faixa etária dos sujeitos . A aplicação do TDCF necessita de folha sulfite branca, lápis preto, borracha, lápis de cor (12 cores diversas), bem como mesa e cadeiras dispostas em uma sala arejada, com boa iluminação e ambiente silencioso.

Foi realizado, através do prontuário do paciente, coleta de dados como identificação (idade, escolaridade e estado civil dos pais), tipo de perda auditiva e comunicação.

Os sujeitos foram informados acerca dos objetivos e procedimentos da pesquisa numa primeira entrevista. As famílias que concordaram com os termos da pesquisa assinaram o Termo de Consentimento. Foram agendadas três entrevistas individuais, com duração máxima de uma hora.

O TDCF foi aplicado individualmente em todos os sujeitos, totalizando 24 desenhos. Solicitou-se a cada participante desenhar sua família: "Faça o desenho colorido de sua família, com você junto, o melhor que você puder, com estes lápis de cor que estão aqui”. Durante a execução do desenho a pesquisadora observou o comportamento do participante através do Roteiro de Observação dos Comportamentos do Sujeito no TDCF. Após o término da atividade proposta, o mesmo foi convidado a responder ao Questionário do TDCF.

\section{RESULTADOS}

A tabela 1 apresenta um panorama sócio demográfico, caracterizando o grupo de sujeitos que participaram da pesquisa. Referente aos adolescentes, observa-se predominância do gênero masculino, com idades variando de 12 a 18 anos, prevalecendo pares de 12, 14 e 15 anos. Em relação à escolaridade, todos se encontram matriculados em escola pública, com predominância no Ensino Fundamental Incompleto. Enquanto para a localização dos mesmos na constelação familiar, há uma distribuição equilibrada quanto à ordem de nascimento dos adolescentes na família. A faixa etária das mães abrange dos 32 aos 59 anos, enquanto que a dos pais vai dos 36 aos 64 anos. Em relação ao nível de instrução, quatro genitores completaram o ensino fundamental, seis deles não o completaram, cinco outros finalizaram o ensino médio, e apenas um deles tem ensino superior incompleto. Quanto à profissão, sete mães são do lar, e uma exerce função de nível médio de escolaridade. No grupo dos pais, sete são profissionais de nível médio e um está aposentado. As famílias apresentam heterogeneidade com relação ao número de filhos, constituídas de 1 a 5 membros fraternos, sendo 3 famílias compostas de fratria com 4 membros, 2 famílias com 2, e as demais com 1, 3 e 5. 
Tabela 1: Dados sócio-demográficos dos adolescentes e suas famílias

\begin{tabular}{|c|c|c|c|c|c|c|c|c|c|}
\hline & Sujeitos & 1 & 2 & 3 & 4 & 5 & 6 & 7 & 8 \\
\hline & \multicolumn{9}{|l|}{ Categorias } \\
\hline SU & Sexo & M & M & $\mathrm{F}$ & M & $\mathrm{F}$ & $\mathrm{F}$ & M & M \\
\hline $\mathrm{JE}$ & Idade & $14 ; 11$ & $15 ; 11$ & $12 ; 08$ & $15 ; 09$ & $12 ; 01$ & $13 ; 02$ & $18 ; 04$ & $14 ; 09$ \\
\hline I & Escolaridade & EFI & EMI & EFI & EMI & EFI & EFI & EMI & EFI \\
\hline TO & Const. Familiar & +velho & FilhoÚnico & DoMeio & DoMeio & +velho & +Novo & +Novo & + Novo \\
\hline $\mathrm{F}$ & Idade Mãe & 42 & 33 & 39 & 37 & 32 & 40 & 59 & 46 \\
\hline A & NI Mãe & EM & EM & ESI & EFI & $\mathrm{EF}$ & $\mathrm{EF}$ & EFI & EFI \\
\hline M & Ocup. Mãe & B & $\mathrm{B}$ & A & B & $\mathrm{B}$ & $\mathrm{B}$ & $\mathrm{B}$ & $\mathrm{B}$ \\
\hline Í & Idade Pai & 42 & 47 & 40 & 42 & 36 & 42 & 64 & 43 \\
\hline $\mathrm{L}$ & NI Pai & EM & EM & EM & EFI & EFI & EFI & $\mathrm{EF}$ & $\mathrm{EF}$ \\
\hline I & Ocup. Pai & A & A & A & A & A & A & $\mathrm{C}$ & A \\
\hline A & $\mathrm{N}^{\circ}$ Filhos & 2 & 1 & 3 & 4 & 2 & 4 & 5 & 4 \\
\hline
\end{tabular}

Nível de Instrução - EF: Ensino Fundamental; EFI: Ensino Fundamental Incompleto; EM: Ensino Médio; EMI: Ensino Médio Incompleto. Ocupações - A: Prof. Nível Médio; B: do lar e não habilitado; C: aposentado.

A tabela 2 aponta as diferentes classificações de perda auditiva, demonstrando variabilidade de perda de audição, sendo esta predominantemente de grau leve a moderada. Verifica-se que todos os sujeitos da pesquisa fazem uso de comunicação oral.

Após análise obtida através do Teste do Desenho em Cores da Família ${ }^{1}$ e demais formulários de avaliação como a Ficha de Identi- ficação, o Roteiro de Observação do Sujeito (Anexo 1), o Quadro Referencial para análise do TDCF (Anexo 2) bem como a Folha de Avaliação, contendo as dimensões interacionais, é possível descrever os componentes emocionais e dificuldades envolvidas na dinâmica familiar de adolescentes portadores de deficiência auditiva, finalidade na qual se baseou a presente pesquisa.

Tabela 2: Classificação do tipo de perda auditiva e comunicação

\begin{tabular}{ccccccccc}
\hline & 1 & 2 & 3 & 4 & 5 & 6 & 7 & 8 \\
\hline OD & C.G. L & NS.G.S & C.G.L / S & NS. L /M & N & C.G. L /S & M.G.L /M & NS.L/ P \\
OE & N & NS.G.S & NS.G.S & SC.G.L / S & NS. L /M. & C.G. L /S & C.G.L /M & NS.L/ P \\
Com. & Oral & Oral & Oral & Oral & Oral & Oral & Oral & Oral \\
\hline
\end{tabular}

OD - ouvido direito; OE: ouvido esquerdo; N: Normal; CGL: Perda condutiva de grau leve; NSGS: Perda sensório neural de grau severo; CGL/S: Perda condutiva de grau leve a severa; NSL/M: Perda sensório neural de grau leve a moderada; MGL/M: Perda mista de grau leve a moderada; CGL/M: Perda condutiva de grau leva a moderada; NSGL: Perda sensório neural de grau leve; NSL/P: Perda sensório neural de grau leve a profunda. Com: Comunicação. 
No que se refere ao panorama geral da dinâmica familiar do adolescente portador de deficiência auditiva, ficou evidenciado que as dimensões disfuncionais significativas foram em relação à comunicação, conflitos, afeição e integração.

A inadequação comunicativa está relacionada com a falta de diálogo construtivo, consequentemente não há uma orientação adequada por parte dos pais sobre alguns assuntos. O tema sexualidade não é conversado, grande parte dos pais acredita que a televisão e a escola abordam o assunto sem necessidade de maiores esclarecimentos. Já na questão drogadição os pais comentam sobre vizinhos, familiares ou amigos quando algum fato significativo ocorre sobre o uso de toxinas.

Fato evidenciado na resposta de um dos adolescentes, bem como de seus pais, a pergunta 25 (referente ao diálogo na família) do questionário (Anexos 3 e 4): Adolescente "Sim. Assistindo a TV quando passa o jornal, falamos dos assuntos que passa. Ninguém conversa disso.” Mãe: “Muito pouco. Contamos o que acontece no serviço. Mais ou menos, só comentários, do fulano que usa droga ou da que engravidou, não tem orientação não" Pai: Sim, assuntos do serviço e da TV. A mãe que conversa com eles.”

Os conflitos existentes, geralmente, estão relacionados ao subsistema conjugal, devido à disfunção comunicativa decorrente das diferentes posturas do casal em relação aos assuntos familiares. Cada um baseia-se na sua postura diante da vida guiando-se pelos valores e conceitos apreendidos em suas famílias de origem. Na maioria dos desenhos o casal aparece entre os filhos, separados.

Já os conflitos ao subsistema parental, ocorrem diante da dificuldade dos pais em lidar com a fase da adolescência e em decorrência da deficiência auditiva. O fato de ter um membro familiar deficiente gera insegurança e medo nos pais, os quais superprotegem o filho, privando-o de realizar atividades esperadas nesta fase. Dessa forma, o adolescente sen- te-se os reprimido e dependente dos pais. Como na fala de um dos adolescentes ao responder à questão 23 sobre pedir permissão para sair (Anexo 3): “ Não tem a decisão é dos dois, querem que eu cuido da casa, não posso sair”

Por fim os conflitos no subsistema fraternal, ocorrem mediante a competição entre os irmãos, gerada pela rivalidade e disputa da atenção dos pais. De um lado os irmãos sentem ciúme pela atenção diferenciada dos pais em relação ao filho deficiente. E do outro o adolescente sente-se inferiorizo por ser o único membro familiar portador de deficiência auditiva. Fator evidenciado na maioria dos desenhos nas quais o adolescente se coloca distante dos demais, ou cercado por paredes, muros ou ainda separado dos irmãos ficando os pais entre eles. Também nas respostas do questionário como relata este adolescente: "Meu irmão” (referente à pergunta 12 sobre ter menos afinidade); “ Ele está adiantado na escola e vai bem em tudo que faz" (referente à pergunta 13 sobre admiração) e “ Meu irmão” (referente à pergunta 18).

Conseqüentemente, a afetividade pouco existe ou se encontra ausente, na maioria das famílias estudadas. Cada membro vive isolado em seus afazeres e compromissos, resultando na falta de integração, enquanto indivíduos pertencentes ao mesmo sistema familiar. Na maioria dos desenhos os membros familiares aparecem distantes ou ainda desenhados lado a lado.

A dimensão individuação apresentou disfuncionalidade, em menor proporção principalmente pelo fato de que os membros ocupam e desempenham seus papéis de forma individualizada, consequentemente pouco interferem na vida do outro. O que dificulta a inter-relação entre os membros, causando disfuncionalidade na comunicação, integração e afetividade.

O sistema familiar apresenta-se, pois, funcional em relação à caracterização dos papéis ocupados por cada membro, estabelecendo-se 
liderança por parte do subsistema parental de maneira saudável. Não há inversão nos papéis desempenhados por cada membro, isto é, os pais assumem o papel de líderes e não delegam as suas responsabilidades para os filhos.

As regras, embora em algumas famílias apresentadas como omissas ou rígidas, no contexto geral são estabelecidas e respeitadas, no que se refere entre outros aos horários, afazeres do lar, organização e cuidados com os pertences. Tal fator é evidenciado também no resultado obtido da dimensão interacional agressividade, devido à maioria dos membros familiares não apresentar comportamentos agressivos significativos.

Em relação à auto-estima, o contexto familiar não apresenta resultado significativo para ser considerado disfuncional, mas o fato de o adolescente ser portador de deficiência auditiva, como fator isolado enquanto indivíduo gera o sentimento de baixa auto-estima apenas no adolescente.

As tabelas 3, 4 e 5 demonstram os resultados obtidos na pesquisa, nos diferentes grupos familiares estudados: adolescentes, mães e pais respectivamente.

A tabela 3 indica as dimensões disfuncionais no sistema familiar sob a ótica dos adolescentes, na qual o subsistema parental apresenta-se como o mais disfuncional. Enquanto que os subsistemas conjugal e fraternal com menos disfuncionalidade, sucessivamente. O funcionamento familiar fica caracterizado pela disfuncionalidade em relação à vulnerabilidade na integração e conflitos intensos sem soluções construtivas, falta de comunicação produtiva e carência afetiva. Em menor proporção referente à individuação dos membros, há freqüência similar entre todos os subsistemas, seguida da auto-estima.

Em contrapartida, o sistema familiar apresenta funcionalidade na caracterização dos papéis, liderança baseada na hierarquia e res- peito para com as regras estabelecidas, de forma pouco agressiva.

A tabela 4 indica as dimensões disfuncionais no sistema familiar sob a ótica das genitoras, na qual o subsistema parental apresenta-se como o mais disfuncional, com maior ênfase em relação ao pai, sendo a relação fraternal considerada com menor grau de disfuncionalidade. O funcionamento familiar fica caracterizado pela disfuncionalidade em relação à falta de comunicação, conflitos intensos sem soluções construtivas, empobrecimento afetivo e vulnerabilidade na integração.

Em contrapartida, o sistema familiar apresenta funcionalidade na caracterização dos papéis, liderança baseada na hierarquia e respeito para com as regras estabelecidas, de maneira pouco agressiva, sendo a individualidade e auto-estima preservada.

A tabela 5 indica as dimensões disfuncionais no sistema familiar sob a ótica dos genitores, no qual o subsistema parental apresenta-se como o mais disfuncional, com maior ênfase em relação ao pai, apresentando diferença significativa em relação aos subsistemas conjugal e fraternal. O funcionamento familiar fica caracterizado pela disfuncionalidade em relação à falta de comunicação, vulnerabilidade na integração e conflitos intensos sem soluções construtivas, na mesma proporção, e carência afetiva.

Em contrapartida, o sistema familiar apresenta funcionalidade na caracterização dos papéis, liderança baseada na hierarquia e respeito para com as regras estabelecidas, de maneira pouco agressiva, a auto-estima preservada, contendo apenas pequena alteração referente à individualidade dos membros.

Após análise das tabelas 3, 4 e 5 verifica-se, a similaridade em ambos os grupos referente ao subsistema parental como o mais disfuncional, predominando a relação do pai com uma pequena diferença em relação à mãe. Enquanto que os subsistemas conjugal e fraternal apresentam menor disfuncionalidade, 
Tabela 3: Dados referentes aos adolescentes

\begin{tabular}{|c|c|c|c|c|c|c|c|}
\hline & \multicolumn{2}{|l|}{ CONJUGAL } & \multicolumn{2}{|c|}{ PARENTAL } & \multicolumn{2}{|c|}{ FRATERNAL } & \multirow[t]{2}{*}{ TOTAL } \\
\hline & $\mathrm{N}$ & $\%$ & $\mathrm{~N}$ & $\%$ & $\mathrm{~N}$ & $\%$ & \\
\hline & & & PAI & MÃE & & & \\
\hline Comunicação & 7 & 70 & 770 & 770 & 6 & 60 & 27 \\
\hline Regras & 0 & 0 & 660 & 660 & NP & NP & 12 \\
\hline Papéis & 0 & 0 & $0 \quad 0$ & $0 \quad 0$ & 0 & 0 & 0 \\
\hline Liderança & 2 & 20 & $\begin{array}{ll}0 & 0\end{array}$ & $\begin{array}{ll}0 & 0\end{array}$ & 0 & 0 & 02 \\
\hline Conflitos & 8 & 80 & 770 & 770 & 6 & 60 & 28 \\
\hline Agressividade & NP & NP & 330 & 220 & $\mathrm{NP}$ & NP & 05 \\
\hline Afeição & 7 & 70 & 770 & 770 & 6 & 60 & 27 \\
\hline Individuação & 5 & 50 & 550 & 550 & 5 & 50 & 20 \\
\hline Integração & 7 & 70 & 770 & 770 & 7 & 70 & 28 \\
\hline Auto-Estima & 2 & 20 & 440 & 440 & 5 & 50 & 15 \\
\hline TOTAL & 38 & 46 & 45 & 35 & & & \\
\hline
\end{tabular}

(NP- não pertinente)

Tabela 4: Dados referentes as genitoras

\begin{tabular}{|c|c|c|c|c|c|c|c|}
\hline & \multicolumn{2}{|c|}{ CONJUGAL } & \multicolumn{2}{|c|}{ PARENTAL } & \multicolumn{2}{|c|}{ FRATERNAL } & \multirow[t]{2}{*}{ TOTAL } \\
\hline & $\mathrm{N}$ & $\%$ & $\mathrm{~N}$ & $\%$ & $\mathrm{~N}$ & $\%$ & \\
\hline & & & PAI & MÃE & & & \\
\hline Comunicação & 8 & 80 & 880 & 880 & 7 & 70 & 31 \\
\hline Regras & 3 & 30 & 440 & 330 & 2 & 20 & 12 \\
\hline Papéis & 0 & 0 & $\begin{array}{ll}0 & 0\end{array}$ & 00 & 0 & 0 & 0 \\
\hline Liderança & 2 & 20 & NP NP & 00 & 0 & 0 & 02 \\
\hline Conflitos & 8 & 80 & 880 & 770 & 7 & 70 & 30 \\
\hline Agressividade & 3 & 30 & 550 & 440 & NP & NP & 12 \\
\hline Afeição & 7 & 70 & 770 & 770 & 7 & 70 & 28 \\
\hline Individuação & 3 & 30 & 330 & 330 & 3 & 30 & 12 \\
\hline Integração & 6 & 60 & 770 & 770 & 7 & 70 & 27 \\
\hline Auto-Estima & 2 & 20 & 220 & 220 & 2 & 20 & 08 \\
\hline TOTAL & 42 & 44 & 41 & 35 & & & \\
\hline
\end{tabular}

(NP- não pertinente) 
Tabela 5: Dados referentes aos genitores

\begin{tabular}{|c|c|c|c|c|c|c|c|}
\hline & \multicolumn{2}{|c|}{ CONJUGAL } & \multicolumn{2}{|c|}{ PARENTAL } & \multicolumn{2}{|c|}{ FRATERNAL } & \multirow[t]{2}{*}{ TOTAL } \\
\hline & $\mathrm{N}$ & $\%$ & $\mathrm{~N}$ & $\%$ & $\mathrm{~N}$ & $\%$ & \\
\hline & & & PAI & MÃE & & & \\
\hline Comunicação & 7 & 70 & 880 & 770 & 7 & 70 & 29 \\
\hline Regras & 0 & 0 & 440 & 220 & NP & NP & 06 \\
\hline Papéis & 0 & 0 & $0 \quad 0$ & $0 \quad 0$ & 0 & 0 & 0 \\
\hline Liderança & NP & NP & 330 & 220 & $\mathrm{NP}$ & NP & 05 \\
\hline Conflitos & 6 & 60 & 770 & 660 & 5 & 50 & 24 \\
\hline Agressividade & 0 & 0 & 330 & 220 & 0 & 0 & 05 \\
\hline Afeição & 7 & 70 & 880 & 770 & 6 & 60 & 28 \\
\hline Individuação & 4 & 40 & 440 & 440 & 4 & 40 & 16 \\
\hline Integração & 7 & 70 & 770 & 770 & 7 & 70 & 28 \\
\hline Auto-Estima & 2 & 20 & 440 & NP NP & NP & NP & 06 \\
\hline TOTAL & 42 & 44 & 41 & 35 & & & \\
\hline
\end{tabular}

(NP- não pertinente)

sucessivamente. As dimensões interacionais comunicação, afeição, integração e conflitos prevaleceram, também, em todos os grupos contendo disfunções.

\section{DISCUSSÃO}

Através da realização deste estudo foi possível verificar os componentes emocionais e dificuldades envolvidas, obtendo-se um panorama geral e específico da dinâmica familiar do adolescente portador de deficiência auditiva.

A abordagem sistêmica no contexto familiar possibilita a compreensão das relações familiares através da funcionalidade e disfuncionalidade entre todos os subsistemas (conjugal, parental e fraternal), abrangendo não só a dimensão do todo, bem como das particularidades envolvidas. Dessa forma, a família é compreendida a partir de uma visão integrada baseada no conceito de causalidade circular. ${ }^{2}$

O conceito de família, bem como os princípios básicos de seu funcionamento abordados por Relvas ${ }^{6}$; Nichols et $\mathrm{al}^{3}$; Cerveny ${ }^{4} \mathrm{e}$ Dessen et $\mathrm{al}^{5}$ foram fundamentais para o estudo das famílias participantes deste estudo. Foi possível comprovar que há influência mútua entre os membros, bem como as trocas com o meio externo e sua interferência no sistema familiar.

A fase do ciclo vital na adolescência, descrita por Carter et $\mathrm{al}^{7}$, auxiliou na análise dos resultados à medida que, através desta literatura, constatou-se que o relacionamento entre pais e adolescentes deve ter clareza na comunicação com base no diálogo harmônico e coerente, tanto no discurso como nas atitudes dos pais. Se essa fase será mais ou menos tumultuada, dependerá da formação da personalidade do adolescente, como enfrentou as 
fases anteriores junto com a família nuclear, família de origem e convivência social, bem como os aspectos emocionais da deficiência auditiva. Assim sendo, é imprescindível que a função familiar na fase adolescente seja cumprida, proporcionando a proteção e a flexibilidade para o crescimento e amadurecimento do adolescente.

Verificou-se como os pais lidam com assuntos pertinentes ao desenvolvimento do filho(a) em relação à sexualidade e à drogadição.

Na maioria das famílias deste grupo, os pais acreditam que tanto a televisão como a escola transmite o suficiente sobre o tema sexualidade e demonstram constrangimento, dificuldade e despreparo ao abordarem o assunto. Dados já previstos na literatura, como nos estudos de Vitiello et $\mathrm{al}^{11}$; Jesus et $\mathrm{al}^{10}$; Nascimento et al ${ }^{12}$ nos quais os resultados obtidos apontam que há dificuldade por parte dos pais em abordar o assunto e que a maioria dos adolescentes trocam informações entre os amigos. Isto ocorre segundo Vitiello et $\mathrm{al}^{8}$ devido ao contexto histórico de repressão sexual que vigorou durante anos e a liberdade da vida moderna. Resultando em conflitos na sexualidade dos pais que conseqüentemente sentem-se despreparados para orientarem seus filhos.

O tema drogadição não gera desconforto nos pais ao abordarem o assunto como ocorre com o tema sexualidade, mas a maioria apenas comenta sobre os noticiários e solicitam que o filho(a) não siga o caminho do vício.

Em algumas famílias pesquisadas, o alcoolismo, o cigarro e o uso de drogas ilícitas por parte dos pais e/ou irmãos dos adolescentes, foram fatores evidenciados como geradores de conflitos entre os membros. Devido à mensagem contraditória ao solicitar que não usem drogas, mas terem o exemplo contrário dentro de casa. Conforme aponta Tiba ${ }^{13-15}$ na literatura, através de sua experiência profissi- onal e estudos realizados, o ambiente familiar é fundamental para que o adolescente tenha referências positivas mas nem sempre é o que ocorre. Há famílias em que pais ou outros membros fazem uso de drogas facilitando que seus filhos tenham este modelo como referência. Ou ainda ambientes hostis que proporcionam a falta de diálogo e compreensão provocando desestrutura emocional nos adolescentes.

Também averiguou-se como o adolescente visualiza esta fase e sente-se em relação às atitudes dos pais, através da avaliação do desenho em cores da família e respostas obtidas no questionário. A maioria manifestou sentir-se reprimida, não tendo liberdade para realizar atividades como sair sem a companhia de um adulto ou passear com os amigos. Conseqüentemente, os sentimentos de insegurança e dependência fazem-se presentes, à medida que são privados de demonstrarem suas reais capacidades. O fato de ser portador de deficiência auditiva o faz sentir diferente dos irmãos, ocasionando comparações e desejo de ser igual aos demais. Souza ${ }^{17}$ aborda, em sua obra, aspectos fundamentais referentes à relação da família com a deficiência auditiva.

De acordo com os resultados desta investigação científica ficou evidente que os pais superprotegem o filho(a), pois acreditam que, apesar da idade, o fato da deficiência auditiva o torna mais frágil e suscetível; dados já previstos na literatura por Souza ${ }^{17}$ (1982). A deficiência auditiva gera componentes emocionais que envolvem a estrutura familiar. Os pais necessitam lidar com os medos e inseguranças decorrentes da perda auditiva, preparando o adolescente para enfrentar as situações da vida, pois, protegendo-o excessivamente irá privá-lo do aprendizado da autodefesa.

O instrumento utilizado para realização da pesquisa foi o Teste do Desenho em Cores da Família ${ }^{1}$, também usado por Valle ${ }^{21}$ na elaboração de sua tese de doutorado, o qual proporcionou resultados fidedignos à medida que 
é considerada uma técnica projetiva gráfica. O teste proporcionou eficácia enquanto instrumento facilitador das análises realizadas, cada participante obteve a oportunidade de expressar sentimentos e postura diante da constelação familiar na qual está inserido.

O objetivo proposto na execução desta pesquisa foi alcançado à medida que os componentes emocionais e dificuldades envolvidas na dinâmica familiar de adolescentes com deficiência auditiva foram apontados mediante as disfunções interacionais, resultantes das avaliações realizadas. Constatou-se que as dimensões geradoras de maior disfuncionalidade foram a comunicação, conflito, afetividade e integração.

Isto posto, nota-se como a comunicação é imprescindível. Através do diálogo construtivo alcançam-se soluções para conflitos, torna-se possível a promoção das relações afetivas e torna-se gratificante a relação familiar.

$\mathrm{O}$ fato de haver um membro deficiente auditivo na família, outro fator evidenciado como gerador de conflitos, requer cuidados emocionais no enfrentamento e elaboração dos componentes emergidos, principalmente, na fase da adolescência.

Verificou-se, ainda, que os pais necessitam de orientação sobre os temas drogadição e

\section{REFERÊNCIAS}

1. Retondo MFNG. Manual Prático de Avaliação do HTP (casa-árvore-pessoafamília). São Paulo: Casa do Psicólogo; 2000.

2. Minuchin S. Famílias: funcionamento e tratamento. Porto Alegre: Artes Médicas; 1982.

3. Nichols MP, Schwartz RC. Terapia Familiar. Conceitos e Métodos. In: Contexto histórico da terapia familiar. Porto Alegre: Artmed; 1998. p.15-74

4. Cerveny CMO. A família como modelo. Desconstruindo a patologia. Campinas: Livro Pleno; 2000. sexualidade, principalmente para que os abordem de forma construtiva e possam, assim, contribuir para o desenvolvimento educacional do(a) filho(a).

Averiguou-se que o adolescente anseia por momentos de liberdade, ou seja, realizar atividades compatíveis e esperadas de acordo com sua faixa etária. Mas, em contrapartida, a superproteção dos pais, devido à deficiência auditiva, provoca sentimentos de insegurança e dependência no adolescente.

Portanto, o estudo traz contribuições importantes. Incentiva os profissionais e instituições a elaborarem novas pesquisas, bem como propostas de trabalho com atuação no tratamento e prevenção das relações familiares.

Os resultados apontados neste estudo evidenciam a necessidade de trabalhar a relação entre pais e adolescentes para que possam compreender sentimentos, atitudes, comportamentos e todo o contexto referente às diferenças entre às gerações, como os componentes emergidos devido a deficiência auditiva.

A minimização da maioria dessas dificuldades será fato concreto se houver uma reavaliação da importância da convivência familiar sustentada no respeito e no amor.

5. Dessen MA, Braz, MP. A Ciência do Desenvolvimento Humano. Tendências atuais e perspectivas futuras. In: A família e suas inter-relações com o desenvolvimento humano. Porto Alegre: Artmed; 2005. p.113-131.

6. Relvas AP. O ciclo vital da família: perspectiva sistêmica. Porto Alegre: Edições Afrontamento; 1996.

7. Carter B, Mcgoldrick M. As mudanças no ciclo de vida familiar. Porto Alegre: Artes Médicas; 1995.

8. Vitiello N, Conceição ISC, Canella PRB, Cavalcanti RC. Adolescência hoje. São Paulo: Roca; 1988. 
9. Aberastuy A, Knobel M. Adolescência normal. Porto Alegre: Artes Médicas; 1992.

10. Vitiello N, Conceição ISC. Aceitação da vida sexual de filhas adolescentes solteiras: um estudo comparativo. Revista Brasileira de Ginecologia e Obstetrícia. 1988; 10(7).

11. Jesus MCP, Temer VP, Silva MA. A educação sexual realizada na família e na escola: opinião de escolares adolescentes. Revista Brasileira de Sexualidade Humana. 1997; 8(1):133.

12. Nascimento MJC, Romera MLC. Sexualidade, psiquismo e a educação sexual entre pais e filhos adolescentes. Revista Brasileira de Sexualidade Humana. 1999; 10(2):237-250.

13. Tiba I. Puberdade e Adolescência: desenvolvimento biopsicossocial. São Paulo: Agora; 1986.

14. __ Juventude e Drogas: Anjos

Caídos. São Paulo: Integrare; 2007.
15. Adolescentes: Quem Ama Educa! São Paulo: Integrare; 2007.

16. Zagury T. Direitos dos Pais. Construindo cidadãos em tempo de crise. Cidade: Record; 2004.

17. Souza EG. Surdez e significado social. São Paulo: Cortez;1982.

18. Silman S. Silverman CA. Auditory diagnosis: principles and applications, editors. San Diego: Singular; 1997.

19. Motti TFG. A rotina de um centro de referência em deficiência auditiva: perspectivas de pais e profissionais [dissertação]. São Carlos: Universidade Federal de São Carlos; 2000.

20. Férez-Carneiro TF. O papel da família na promoção da saúde mental. Psicologia Hospitalar. 1996; 12(12): 4-9.

21. Valle TGM. Reciprocidade sócio-afetiva da criança com fissura lábio-palatal e sua família [doutorado] São Paulo: Universidade de São Paulo; 2000.

22. Corman L. O teste do desenho da família. São Paulo: Mestre Jou; 1979. 


\section{Anexo 1 - Formulário: observação do comportamento do sujeito no Teste do Desenho em Cores da Família (Desenho e Questionário)}

Aspectos formais do desenho:

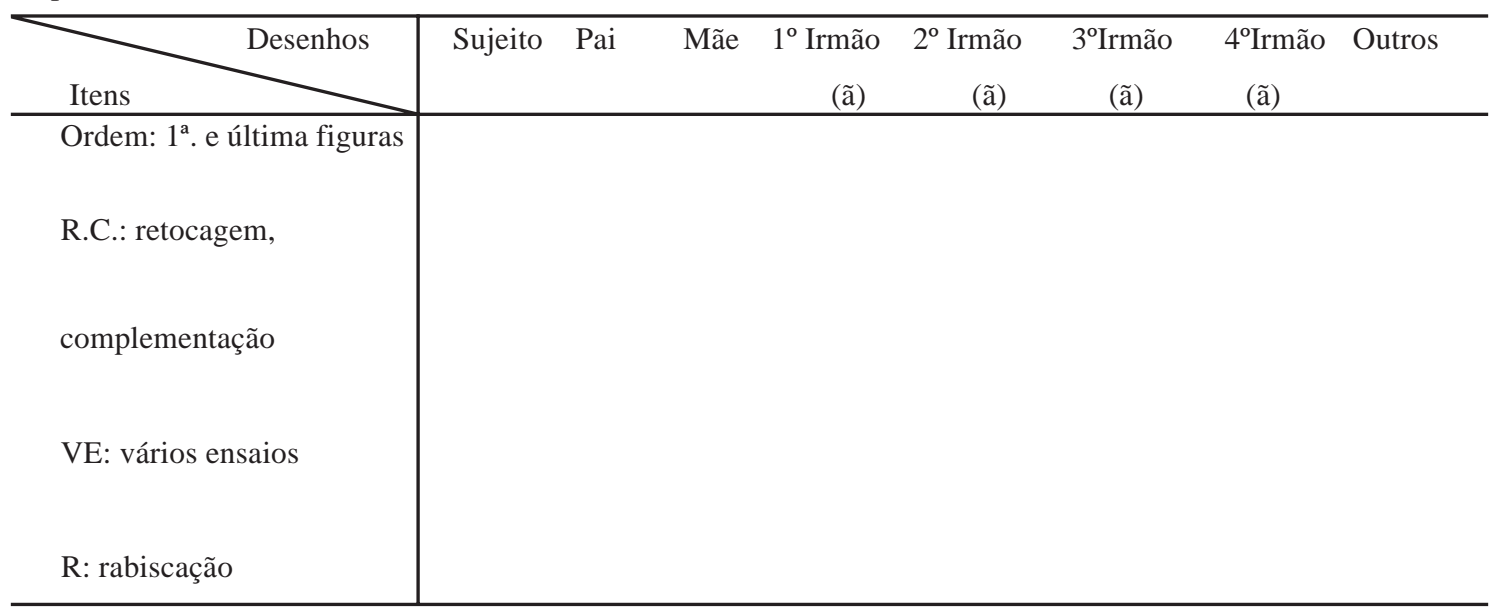

- Cumprimento das ordens (desenha uma família, colore responde às perguntas do questionário).

- Insegurança (formula questões, como: “não sei fazer”. “está bom?”, “o que faço agora”? , fica parado esperando apoio...)

- Inibição (mantém a cabeça baixa, evita o contato olho à olho com o aplicador, esconde o desenho entre os braços, responde por monossílabos ou frases curtas...)

- Cooperação (realiza a tarefa prontamente, interessa-se por ela, sente-se à vontade, faz comentários sobre o que idealiza...)

- Agitação (não para quieto, não permanece na realização do teste...)

- Desmotivação (faz comentários como: “não quero fazer”, “quero ir embora”, “estou com preguiça”, trabalha mecanicamente...)

- Dispersão (distrai-se com barulho fora do local de aplicação da prova, para de realizá-la para fazer perguntas não pertinentes, manifesta-se alheia...)

- Dependência (pergunta pela (o) acompanhante-pai, mãe ou outra pessoa-, quer ver onde se encontra...). 


\section{Anexo 2 - Quadro Referencial para Análise do Teste do Desenho em Cores da Família (Baseado em Becker (1980); Borges (1990); Corman (1979); Cunha e cols. (1993); Maggi (1970) e outros). Elaborado por Pérez Ramos,A}

1. Objetivo Geral: verificar a percepção do examinado (E) de sua família e os sentimentos e atitudes em relação aos membros da mesma. A interpretação do teste deve ter sempre como referência os antecedentes do examinado assim como, a estrutura e a dinâmica de sua família.

(Existência da variável é indicada por X)

\section{VARIÁVEIS}

\section{$\mathbf{X}$}

INTERPRETAÇÃO

1. Tamanho da figuras

- Maior: uma ou mais figuras em relação às demais.

- Igual:a fig.E, como o de outro ou de outras.

- Menor: a fig. E, em relação ao dos outros.

2. Seqüência de Figuras

- Auto-localização: alteração da posição da fig. E na constelação familiar (ex. coloca-se como um bebê, coloca-se no lugar de outro membro).

- Fig. E em primeiro lugar (fora da situação real do espaço)

- Fig. E em último lugar (fora da situação real).

- Invertida (iniciando pela criança de menor idade até alcançar às figuras dos pais).
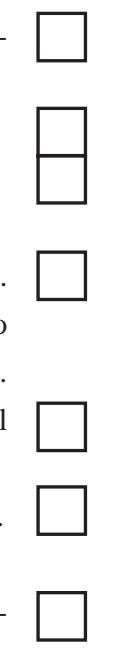

3. Posição das figuras entre si

- Distanciamento (entre figuras)

- Distanciamento da fig.E das outras

- Aproximação da fig.E de uma ou várias delas

- Figuras ligadas (dando-se as mãos, ou linhas que se unem)

4. Omissões

- De figuras essenciais (pais e irmão)

- Da própria fig. E

- Partes do corpo (na fig. E, e/ou em outras)

5. Posição na página

- Parte superior

- Parte inferior
- Dominância e/ou valorização das figuras maiores sobre as outras.

- Competição; identificação

- Baixa auto-estima; sentimento de inferioridade.

- Conflito; regressão; inadequação de si mesmo com a figura trocada.

- Liderança; sentimento de superioridade; desejo de ser valorizado.

- Sentimento de inferioridade; baixa autoestima.

- Desejo de ser valorizado e de ser centro de atenção.

- Desunião; dificuldade na comunicação; distanciamento emocional.

- Sentimento de exclusão; de rejeição ou discriminação.

- Necessidade de apoio, de identificação ou dependência.

- Interdependência; falta de liberdade individual; isolamento grupal

- Conflitos; sentimentos de rivalidade; ciúmes das figuras omitidas.

- Sentimento de ser excluído; rejeitado; não receber afeto dos demais.

- Conflito em relação à parte omitida (fig. E ou nas dos outros), ou dificuldade de relacionamento.

- Expressão de fantasias; sentimento de poder.

- Depressão; insegurança; sentimento de inferioridade. 


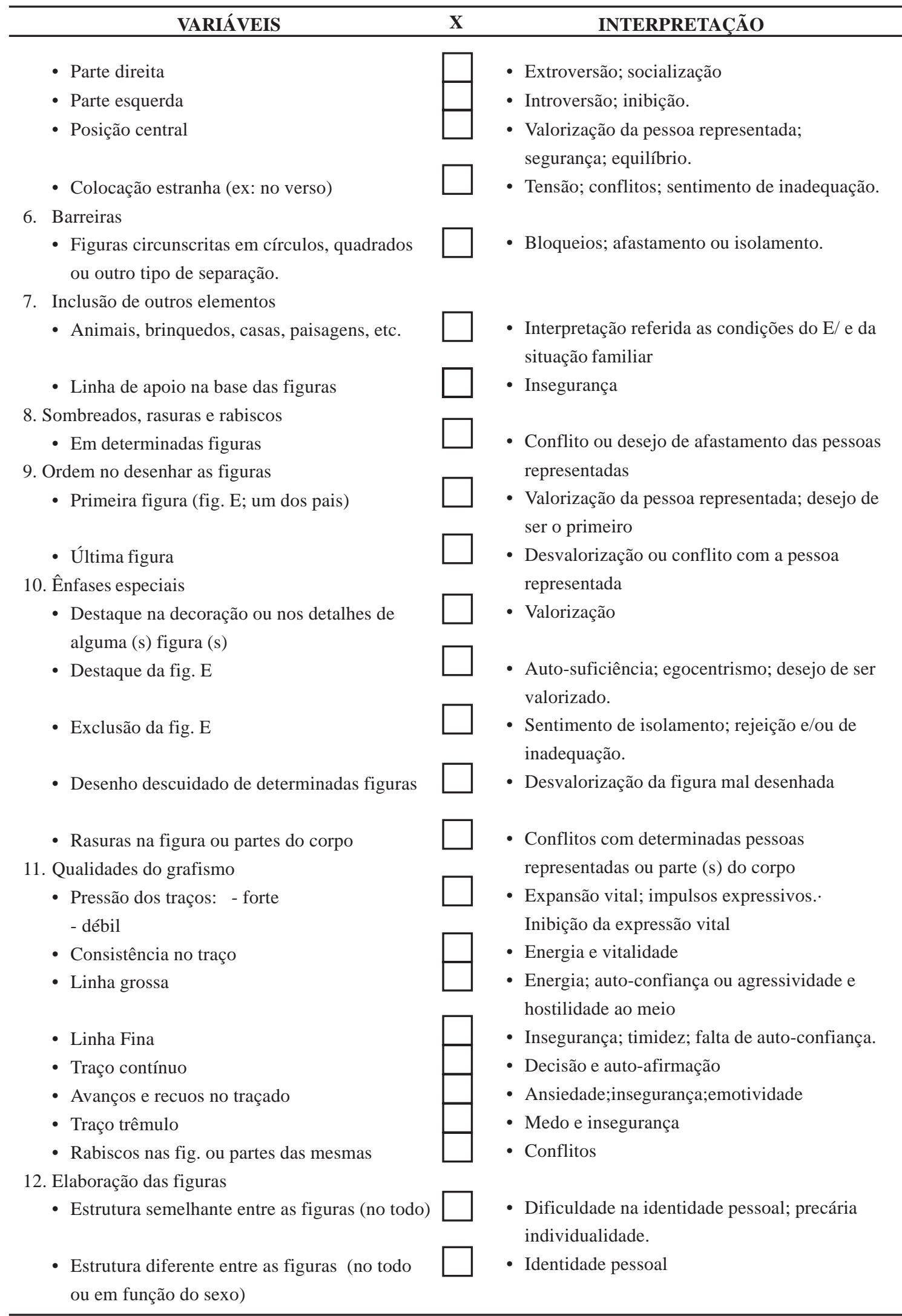




\begin{tabular}{|c|c|c|}
\hline VARIÁVEIS & $\mathbf{X}$ & INTERPRETAÇÃO \\
\hline $\begin{array}{l}\text { - Estrutura semelhante nas figuras paternas e nas } \\
\text { fraternas }\end{array}$ & & $\begin{array}{l}\text { - Distanciamento entre os subsistemas, materno } \\
\text { e fraterno. }\end{array}$ \\
\hline \multicolumn{3}{|l|}{ 13. Colorido } \\
\hline - Apenas a fig. E & & - Valorização da fig. E. \\
\hline $\begin{array}{l}\text { - Cor diferente de uma figura em relação às } \\
\text { demais }\end{array}$ & & $\begin{array}{l}\text { • Determinação; valorização da figura } \\
\text { correspondente. }\end{array}$ \\
\hline $\begin{array}{l}\text { - Cores semelhantes nas figuras paternas e } \\
\text { fraternas (diferentes entre ambos os grupos) }\end{array}$ & & • Diferenciação dos subsistemas da família. \\
\hline - Cores semelhantes nas figuras do próprio sexo & & • Diferenciação sexual \\
\hline • Cores preferidas (utilizadas) & & - Valorização \\
\hline - Cores rejeitadas (utilizadas) & & - Desvalorização \\
\hline
\end{tabular}

\section{Anexo 3 - Questionário (Adolescente)}

1. Quem são estes na família?

2. Esta faltando alguém nesta família?

3. Por que você desenhou primeiro esta figura?

4. Por que você desenhou por último esta figura?

5. Como eles se dão?

6. O que eles estão fazendo?

7. Eles têm lugares certos para comer, dormir ou assirtir televisão?

8. Eles têm horários para fazer as coisas em casa?

9. Com qual dessas pessoas você tem mais afinidade?

10.0 que você mais admira nesta pessoa?

11. O que você menos admira nesta pessoa?

12. Com qual dessas pessoas você tem menos afinidade?

13.0 que você mais admira nesta pessoa?

14. O que você menos admira nesta pessoa?

15. De quem seu pai mais gosta?

16. De quem seu pai menos gosta?

17.De quem sua mãe mais gosta?

18.De quem sua mãe menos gosta?

19. Qual a atitude do seu pai frente aos acertos dos filhos?

20.Qual a atitude do seu pai frente aos erros dos filhos?

21. Qual a atitude de sua mãe frente aos acertos dos filhos?

22. Qual a atitude de sua mãe frente aos erros dos filhos?

23. Quando os filhos necessitam pedir permissão aos pais para saírem, para quem pedem?

24. Destas pessoas que você desenhou, qual delas se parece mais com você?

25. Você e seus pais conversam, dialogam? Quais os assuntos preferidos?

E sobre drogas e sexualidade?

26. Se você tivesse alguma coisa importante para falar, para quem contaria?

27.Por que esta figura está perto de você?

28.Por que esta figura está longe de você?

29. Qual destas cores que usou no desenho, você mais gosta?

30. Qual destas cores que usou no desenho, você menos gosta? 


\section{Anexo 4 - Questionário (Pais)}

1. Quem são estes na família?

2. Esta faltando alguém nesta família?

3. Por que você desenhou primeiro esta figura?

4. Por que você desenhou por último esta figura?

5. Como eles se dão?

6. O que eles estão fazendo?

7. Eles têm lugares certos para comer, dormir ou assirtir televisão?

8. Eles têm horários para fazer as coisas em casa?

9. Com qual dessas pessoas você tem mais afinidade?

10.O que você mais admira nesta pessoa?

11. O que você menos admira nesta pessoa?

12. Com qual dessas pessoas você tem menos afinidade?

13.O que você mais admira nesta pessoa?

14. O que você menos admira nesta pessoa?

15. De quem você mais gosta?

16. De quem você menos gosta?

17. De quem seu marido ou esposa mais gosta?

18. De quem seu marido ou esposa menos gosta?

19. Qual a sua atitude frente aos acertos dos seus filhos?

20. Qual a sua atitude frente aos erros dos seus filhos?

21. Qual a atitude de seu marido ou esposa frente aos acertos dos filhos?

22. Qual a atitude de seu marido ou esposa frente aos erros dos filhos?

23. Quando os filhos necessitam pedir permissão aos pais para saírem, para quem pedem?

24. Destas pessoas que você desenhou, qual delas se parece mais com você?

25.Existe dialogo entre pais e filhos? Quais os assuntos preferidos? E sobre drogas e sexualidade?

26. Se você tivesse alguma coisa importante para falar, para quem contaria?

27.Por que esta figura está perto de você?

28. Por que esta figura está longe de você?

29. Qual destas cores que usou no desenho, você mais gosta?

30. Qual destas cores que usou no desenho, você menos gosta?

Recebido em: 02/03/2008

Modificado em: 22/07/2008

Aceito em: 30/09/2008 